\title{
Optimasi Proses Blansir terhadap Warna dan Vitamin C pada Pengeringan Cabai Merah Keriting (Capsicum annuum L) dengan Tunnel Dehidrator
}

\section{Optimization of the Blanching Process for Color dan Vitamin C in Drying Curly Red Chili (Capsicum annuum L) with Tunnel Dehydrator}

\author{
Hisworo Ramdani ${ }^{1 *}$, Reki Wicaksono Ashadi² dan Narjisul Ummah² \\ 'Pengajar PS Ilmu dan Teknologi Pangan, Fakultas Bioindustri, Universitas Trilogi \\ Peneliti Pusat Kajian Hortikultura Tropika (PKHT) Institut Pertanian Bogor \\ ${ }^{2}$ Program Studi Teknologi Industri Pertanian, Fakultas Ilmu Pangan Halal, Universitas Djuanda Bogor
}

Diterima 13 September 2018/Disetujui 12 Oktober 2018

\begin{abstract}
This study aims to get the maximum uptake condition to produce the best vitamin $C$, color, and water content that was desired. The analysis used in this study uses the Central Composite Design from Response Surface Methodology (RSM). RSM was a tool that can calculate the optimum value of the factors given based on research data or better known as Multiple Variable Functions (FPG). The temperature and blast time as a research experimental factor of the desired response are color and vitamin $C$. The color optimization results showed $Y=17.276-0.945 \times 1+1.787 \times 2-1.638 \times 12-2.619 \times 22+0.934 \times 1 \times 2$ and produce maximum color at optimum temperature and reaction time $85.46(86 \pm 0.5)^{\circ} \mathrm{C}$ and 12 minutes. The optimization results of vitamin $C$ showed $Y=12.144+1.834 x 1+0.117 x 2+1.441 \times 12-1.052 \times 22-1.540 \times 1 \times 2$ and produce maximum vitamin C at optimum temperature and reaction time $98.11(98 \pm 0.5)^{\circ} \mathrm{C}$ and 5 minutes. The results of the validation at the above temperature produce a color of 17.4 and vitamin C $15.2 \mathrm{mg} / 100 \mathrm{~g}$.
\end{abstract}

Keywords: blanch, chili, drying, optimization, RSM

\section{ABSTRAK}

Penelitian ini bertujuan untuk mendapatkan kondisi uptimum blansir agar menghasilkan vitamin C, warna, dan kadar air terbaik yag diinginkan. Analisis yang digunakan pada penelitian ini menggunakan Central Composite Design dari Response Surface Methodology (RSM). RSM merupakan alat yang dapat menghitung nilai optimum dari faktor yang diberikan berdasarkan data penelitian atau lebih dikenal dengan Fungsi Peubah Ganda (FPG). Suhu dan waktu blansir sebagai faktor percobaan penelitian dari respon yang diinginkan yaitu warna dan vitamin C. Hasil optimasi warna adalah $Y=17.276-0.945 x_{1}+1.787 x_{2}-1.638 x_{1}^{2}-2.619 x_{2}^{2}+0.934 x_{T} x_{2}$ dan menghasilkan warna maksimum pada suhu dan waktu reaksi optimum $85,46(86 \pm 0,5)^{\circ} \mathrm{C}$ dan 12 menit. Hasil optimasi vitamin $C$ adalah $Y=12.144+1.834 x_{1}+0.117 x_{2}+1.441 x_{1}{ }^{2}$ $-1.052 x_{2}^{2}-1.540 x_{1} x_{2}$ dan menghasilkan vitamin C maksimum pada suhu dan waktu reaksi optimum $98.11(98 \pm 0.5)^{\circ} \mathrm{C}$ dan 5 menit. Hasil validasi pada suhu diatas menghasilkan warna 17.4 dan vitamin C $15.2 \mathrm{mg} / 100 \mathrm{~g}$.

Kata kunci: blansir, cabai, optimasi, pengeringan, RSM

\section{PENDAHULUAN}

Masalah klasik bagi produk mentah hasil pertanian termasuk hasil pertanian cabai diantaranya adalah kadar air tinggi yang menyebabkan umur simpan pendek sehingga bahan menjadi mudah busuk. Cabai mudah sekali mengalami kerusakan. Keadaan yang sering terjadi adalah harga cabai merah menjadi rendah ketika musim panen raya karena petani menjual seluruhnya. Petani tidak berani

\footnotetext{
* Penulis untuk korespondensi. e-mail: hisworor@gmail.com
}

mengambil resiko untuk menyimpan hasil panennya karena sifat yang mudah rusak (Barus, 2009). Sifat cabai yang mudah mengalami kerusakan dalam keadaan segar tersebut mengindikasikan bahwa perlu dilakukan pengolahan pascapanen agar kerusakan pada cabai dapat diperkecil dan menjamin ketersediaan cabai merah pada saat terjadi kelangkaan cabai merah segar, sehingga dapat meningkatkan nilai tambah dan pendapatan serta kesejahteraan masyarakat khususnya petani dan pelaku usaha.

Salah satu cara penanganan pascapanen cabai adalah dengan dikeringkan. Cabai merah kering utuh merupakan olahan cabai merah segar yang telah mengalami proses pengeringan sehingga terjadi pengeluaran atau pengurangan kandungan air dari bahan tersebut dengan menggunakan 
energi panas. Produk cabai merah kering utuh yang diharapkan berupa cabai merah kering utuh dengan kadar air sampai dengan 11\%dan intensitas warna yang dipertahankan sebaik mungkin. Pengeringan yang banyak dilakukan pada bahan pangan menggunakan suhu yang rendah. Produk diversifikasi hasil olahan dapat meningkatkan umur simpan seperti layaknya melalui pengeringan, dapat menjangkau pasaran yang lebih luas dan lebih terjamin ketersediaannya. Produk kering Indonesia mempunyai prospek pasar yang baik di dalam maupun di luar negeri. Penelitian ini dilakukan untuk menghasilkan cabai merah keriting kering utuh yang memiliki nilai mutu dan dengan kualitas yang dapat diterima oleh pasar.

Produk pangan yang dikeringkan seringkali mengalami beberapa masalah diantaranya adalah terjadinya penurunan kandungan gizi yang sangat drastis, reaksi pencoklatan, serta kadar air yang masih terlalu tinggi sehingga memungkinkan mikroba tumbuh dengan cepat. Keadaan tersebut selain ditentukan oleh kondisi pengeringan, juga sangat ditentukan oleh perlakuan awal yang diberikan sebelum bahan dikeringkan. Perlakuan awal yang dibutuhkan untuk menghindari perubahan yang tidak diinginkan salah satunya dengan cara blansir. Perlakuan blansir harus disesuaikan dengan keadaan bahan yang akan dikeringkan, perlakuan blansir yang tidak tepat pada bahan sebelum dikeringkan justru akan merusak keadaan fisik dan kimia bahan pangan itu sendiri. Proses perlakuan blansir sebelum bahan dikeringkan dipercaya dapat menginaktifasikan enzim polifenoloksidase dalam bahan sehingga dapat mempertahankan warna, dan nilai gizi yang diinginkan, pengeringan yang akan dilakukan pada bahan dapat merusak warna dan nilai gizi bahan yang sudah dikeringkan sehingga perlu dilakukannya proses pra pngeringan (pra perlakuan) yaitu dengan cara blansir.

Penelitian ini bertujuan untuk mendapatkan kondisi optimum pada suhu dan waktu blansir, agar mendapatkan nilai vitamin $\mathrm{C}$ dan warna terbaik pada cabai merah keriting kering. Penelitian yang dilakukan pada pengeringan cabai merah keriting (Capsicum annuum L) yang dikeringkan dengan mesin pengering (tunnel dehidrator), diduga bahwa perbedaan suhu dan waktu pada proses blansir akan mempengaruhi warna dan kandungan vitamin $\mathrm{C}$ pada cabai merah keriting sebelum dan sesudah dikeringkan.

\section{BAHAN DAN METODE}

\section{Alat dan Bahan}

Bahan baku yang digunakan dalam penelitian adalah cabai merah keriting, air, bahan kimia pendukung lain untuk pengujian vitamin $\mathrm{C}$ seperti indikator kanji, aquadest, larutan iod. Alat yang digunakan dalam penelitian adalah tunnel dehidrator, alat steam, timbangan digital (ketelitian $1 \mathrm{gr}$ ), timbangan camry electronik pocket scale model EHA 351 (ketelitian 0.1 gr), termometer, plastik kedap udara, serta alat pendukung untuk pengujian laboratorium seperti oven, cawan, buret, erlenmeyer, gelas ukur, pipet mohr, pipet tetes, gelas piala dan colour reader CR-10 Konica Minolta.

\section{Metode Penelitian}

Penentuan faktor reaksi dilakukan bertujuan untuk mengetahui pengaruh suhu blansir dan lama blansir terhadap kandungan vitamin $\mathrm{C}$ dan warna yang digunakan untuk cabai merah keriting yang dikeringkan. Suhu blansir yang digunakan sebesar $80-95^{\circ} \mathrm{C}$ dan lama blansir sebesar 5-15 menit. Penggunaan rentang suhu dan lama blansir tersebut berdasarkan penelitian terdahulu oleh nursani pada tahun 2008 untuk blansir cabai yang terbaik diberikan pada suhu 90-95 ${ }^{\circ} \mathrm{C}$ selama 5-10 menit, sedangkan untuk pembuatan bubuk cabai rawit merah menggunakan blansir dengan suhu $90{ }^{\circ} \mathrm{C}$ selama 15 menit. Berdasarkan hasil penelitian yang dilakukan nursani, maka rentang suhu yang diambil untuk blansir antara $80{ }^{\circ} \mathrm{C}-95^{\circ} \mathrm{C}$ selama 5-15 menit. Adapun rancangan percobaan yang digunakan adalah rancangan faktorial dua taraf (two level factorial design) dengan nilai tinggi dan rendah untuk masing-masing faktor.

Model rancangan percobaan untuk mengetahui pengaruh faktor linier terhadap respon yang diinginkan adalah sebagai berikut:

$$
Y=a_{o}+\sum_{i=1}^{2} a_{i} X_{i}+\sum_{i<1} a_{j} X_{i} X
$$

Keterangan : $\mathrm{Y}=$ Respon dari masing-masing perlakuan, $\mathrm{X}_{\mathrm{i}}, \mathrm{X}_{\mathrm{j}}=$ Variabel bebas, $\mathrm{a}_{\mathrm{o}}=$ intersep, $\mathrm{a}_{\mathrm{i}}=$ koefisien regresi orde pertama, $\mathrm{a}_{\mathrm{ij}}=$ Koefisien interaksi untuk interaksi variable $\mathrm{i}$ dan $\mathrm{j}$

Penentuan kondisi optimum faktor suhu blansir dan lama blansir terhadap kandungan vitamin $\mathrm{C}$ dan warna dilakukan dengan menganalisis permukaan respon nilai vitamin C dan warna yang dipengaruhi oleh faktor reaksi menggunakan Metode Permukaan Respon (RSM). Model rancangan percobaan untuk mengetahui permukaan respon pengaruh faktor adalah sebagai berikut :

$$
Y=a_{o}+\sum_{i=1}^{k} a_{i} X_{i}+\sum_{i=1, j=2}^{k-1, k} a_{i, j} X_{i} X_{j}+\sum_{i=1}^{k} a_{i} X_{i}^{2}+\mathrm{e}
$$

Keterangan: $\mathrm{Y}=$ respon pengamatan, $\mathrm{a}_{\mathrm{o}}=$ intersep, $\mathrm{a}_{\mathrm{i}}=$ pengaruh linier, $\mathrm{a}_{\mathrm{ii}}=$ pengaruh kuadratik, $\mathrm{a}_{\mathrm{ij}}=$ pengaruh interaksi percobaan, $\mathrm{X}_{\mathrm{i}}=$ kode untuk faktor ke-i, $\mathrm{X}_{\mathrm{j}}=$ kode untuk faktor ke-j, $k=$ jumlah faktor yang dicobakan

\section{Pelaksanaan Penelitian}

Persiapkan cabai merah keriting sebanyak $3 \mathrm{~kg}$ lalu dilakukan penyortiran terhadap cabai rusak dan cabai utuh. Cabai utuh dicuci dan ditiriskan, kemudian ditimbang sebanyak 150 gram pada masing-masing perlakuan. Setiap sampel dilakukan perlakuan blansir dengan suhu $80{ }^{\circ} \mathrm{C}$ dan $95{ }^{\circ} \mathrm{C}$ dengan suhu 5 menit dan 15 menit dan diberi kode label $(-1,-1),(-1,1),(1,-1),(1,1),(0,0),(0,0),(0,0),(0,0)$, $(0,0),(-1.4,0),(1.4,0),(0,-1.4),(0,1.4)$. Cabai dihamparkan pada rak pengering dan dikeringkan selama 8 jam pada suhu $70{ }^{\circ} \mathrm{C}$. Suhu pengeringan berdasarkan penelitian 
pendahuluan yang dilakukan pada cabai merah keriting yang menghasilkan kadar air sebesar $10 \%$ (db) dengan rendemen mencapai $22 \%$. Cabai yang sudah dikeringkan dan dianalisis kimia warna, vitamin $\mathrm{C}$ dan kadar air.

Alat pengering (tunnel dehidrator) disiapkan dengan mengatur suhu dan waktu pengeringan yaitu $70{ }^{\circ} \mathrm{C}$ dan 8 jam. Kadar air cabai kering harus lebih kecil atau sama dengan sebesar 11\%. Alat-alat laboratorium untuk analisis kimia. Analisis sampel dilakukan untuk mengetahui pengaruh faktor reaksi suhu blansir (X1) dan lama blansir (X2) terhadap variabel respon yang diinginkan. Analisis sampel dilakukan pada cabai merah keriting segar sebelum dilakukan blansir untuk mengetahui kondisi awal cabai dan cabai merah keriting setelah diblansir dan dikeringkan menggunakan mesin pengering tunnel dehidrator. Variabel respon yang diinginkan pada penelitian ini meliputi : Kadar air (AOAC, 1984), kadar vitamin C (Jacobs, 1985), dan pengukuran warna (Hunter, 1999). Variabel respon dipilih berdasarkan pengaruh faktor reaksi terhadap sifat dan karakteristik respon yang rentan terhadap pemberian panas.

\section{HASIL DAN PEMBAHASAN}

\section{Karakteristik Nilai Gizi Cabai Merah Keriting}

Cabai merah keriting (Capsicum annuum L) yang digunakan pada penelitian adalah cabai merah keriting dengan varietas TM 999 yang banyak dijual di pasar tradisional. Kondisi cabai ini memiliki diameter lebih besar dibanding cabai merah keriting lainnya. Cabai merah keriting segar sebelum mendapatkan perlakuan dianalisis terlebih dahulu untuk mengetahui kondisi awal nilai gizi yang dimiliki cabai merah keriting sebagai bahan penelitian.

\section{Pengaruh Faktor Reaksi}

Pengaruh faktor reaksi merupakan respon dari perlakuan yang diberikan terhadap bahan penelitian (cabai merah keriting) sesudah pengeringan. Faktor yang diberikan pada cabai yaitu suhu blansir (X1) dan waktu blansir (X2). Reaksi atau respon yang dihasilkan dalam penelitian ini meliputi warna cabai (chroma) dan nilai vitamin $\mathrm{C}$. Disamping itu juga dilakukan pengamatan terhadap nilai rendemen dan kadar air. Kadar air merupakan parameter respon yang penting karena kadar air yang dimiliki cabai kering harus sesuai dengan standar mutu internasional ( SNI 01-3389-1994).

\section{Kadar Air Cabai Merah Keriting}

Hasil analisis kadar air yang dilakukan pada cabai yang diberi perlakuan blansir dan dikeringkan dengan mesin pengering. Hasil analisis menunjukan bahwa faktorfaktor reaksi yang digunakan yaitu suhu (X1), lama blansir (X2) dan interaksi kedua faktor tidak memberikan pengaruh yang signifikan terhadap kadar air cabai merah keriting kering, hal ini menunjukkan bahwa nilai kadar air cabai kering memiliki kisaran nilai yang cenderung sama, namun rata-rata kadar air dengan perlakuan blansir memiliki nilai kadar air lebih kecil dibanding kadar air pada cabai tanpa perlakuan blansir yang dikeringkan.

Pada saat blansir sebagian air terikat yang terkandung pada bahan berubah menjadi uap. Bila suhu air meningkat, jumlah rata-rata molekul air dalam kerumunan molekul air menurun dan ikatan hydrogen putus dan terbentuk lagi secara cepat. Bila air dipanaskan lebih tinggi lagi sehingga molekul-molekul air bergerak demikian cepat dan tekanan uap air melebihi tekanan atmosfer, beberapa molekul dapat melarikan diri dari permukaan dan menjadi gas. Hal ini terjadi ketika air mendidih pada suhu $100{ }^{\circ} \mathrm{C}$. Molekulmolekul air kurang lebih menjadi bebas satu sama lainnya dalam keadaan berupa uap (Winarno, 1991). Normal plot kadar air cabai kering dapat dilihat pada Gambar 1.

Kadar air yang diinginkan adalah kadar air dengan persentase terkecil, agar pada saat cabai dikeringkan nilai kadar air yang diinginkan mudah tercapai yaitu di bawah 11\% (SNI 01-3389-1994). Contour plot untuk kadar air cabai merah keriting kering dapat dilihat pada Gambar 2. Contour plot menggambarkan nilai kadar air yang akan dicapai untuk tingkatan suhu dan waktu blansir yang diberikan. Target yang diinginkan adalah nilai persentase rendah sehingga terlihat pada gambar bahwa area terbanyak yang akan dicapai yaitu pada kadar air 7-8\% basis kering dengan waktu kurang dari 12 menit pada semua sebaran suhu $\left(80-95^{\circ} \mathrm{C}\right)$. Gambar surface dan contour plot pada kadar air merupakan kasus yang terjadi model linier pada (orde satu) terdapat lack of fit, sehingga model orde dua yang diujikan tidak mencukupi maka akan memperoleh hasil linear pada salah satu faktor dan non-linear pada faktor yang lain yang mengakibatkan gagal untuk dapat memperoleh titik optimum.

Kadar air yang dimiliki cabai setelah cabai dikeringkan pada penelitian sebagian besar masuk kriteria mutu SNI cabai kering, dibawah $11 \%$ basis kering. Gambar 3 menunjukkan surface plot yang dimiliki cabai merah kering terhadap nilai kadar air. Kadar air yang dimiliki cabai merah keriting kering dibawah 12\% untuk faktor suhu (X1) dan lama blansir (X2) yang digunakan. Kadar air yang diinginkan merupakan kadar air yang paling rendah, karena semakin besar kadar air

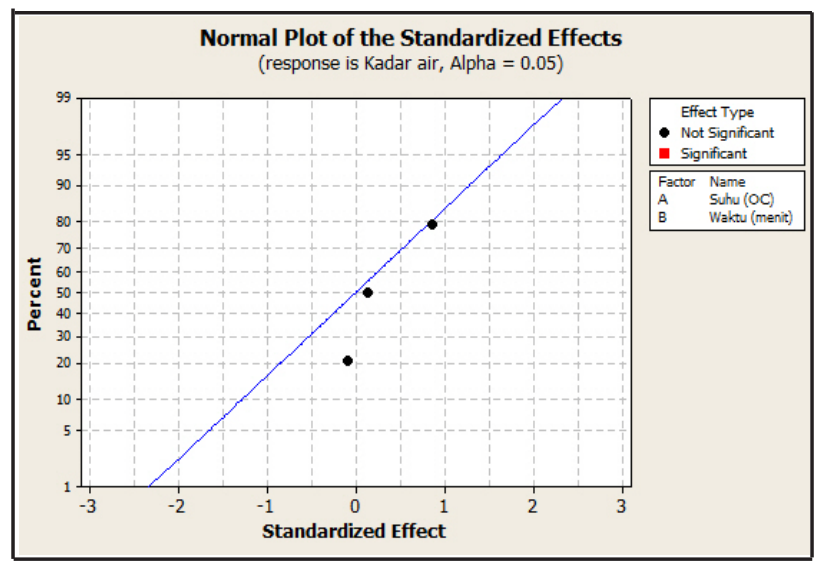

Gambar 1. Normal plot kadar air cabai kering 
yang dimiliki maka mutu produk cabai kering tidak sesuai dengan SNI, karena kadar air dibawah 11\% memiliki sedikit kemungkinan perkembangbiakan mikroba yang membuat bahan pangan rusak. Analisis yang dilakukan menggunakan metode oven atau alat pengering lainnya. Analisis oven merupakan analisis dengan metode langsung, metode ini memiliki ketelitian yang tinggi. Analisis kadar air dengan metode oven didasarkan atas berat yang hilang.

\section{Vitamin C Cabai Merah Keriting}

Berdasarkan hasil penelitian blansir dapat mencegah kehilangan vitamin $\mathrm{C}$ selama pengeringan dan penyimpanan. Nilai vitamin $\mathrm{C}$ cabai merah keriting yang dikeringkan memiliki peningkatan yang cukup signifikan dari cabai merah keriting tanpa perlakuan blansir. Normal plot vitamin C cabai merah keriting kering ditunjukkan pada Gambar 4. Gambar 4 menunjukkan bahwa faktor interaksi suhu (X1) dan lama blansir (X2) berpengaruh nyata terhadap vitamin $\mathrm{C}$ pada cabai kering. Interaksi pengaruh faktor suhu dan waktu terhadap vitamin $\mathrm{C}$ dapat dilihat pada Gambar 5. Interaksi antara suhu maksimum dan suhu minimum blansir dengan waktu terhadap vitamin $\mathrm{C}$ berlawanan arah, suhu $95{ }^{\circ} \mathrm{C}$ dengan waktu rendah (sebentar) menghasilkan nilai vitamin $\mathrm{C}$ yang cukup besar, sedangkan suhu $80{ }^{\circ} \mathrm{C}$ dengan waktu lama yang akan memberikan nilai vitamin $\mathrm{C}$ tinggi.

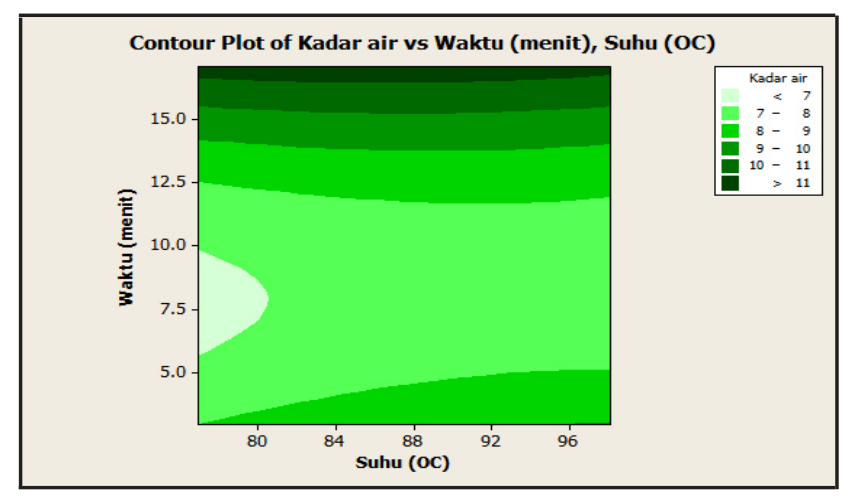

Gambar 2. Contour plot kadar air cabai kering

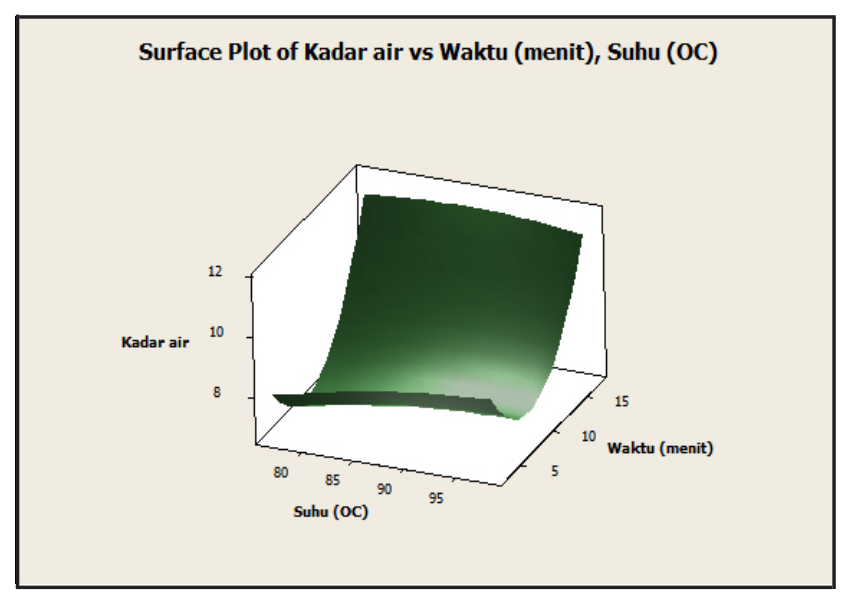

Gambar 3. Surface plot kadar air cabai kering
Jika suhu tinggi dalam waktu lama maka akan menghasilkan nilai vitamin C rendah, sedangkan apabila suhu rendah dalam waktu sebentar maka akan menghasilkan nilai vitamin $\mathrm{C}$ yang lebih rendah lagi.

Vitamin C mudah larut dalam air dan mudah rusak oleh oksidasi, panas, dan alkali, sehingga pada saat pemberian panas tinggi dalam waktu lama maka nilai vitamin $\mathrm{C}$ menurun. Vitamin merupakan suatu molekul organik yang sangat diperlukan tubuh untuk proses metabolisme dan pertumbuhan yang normal (Winarno, 1991). Contour plot vitamin $\mathrm{C}$ pada cabai kering ditunjukkan pada Gambar 6. Area nilai vitamin $\mathrm{C}$ yang dimiliki oleh cabai merah keriting kering, nilai 11-12 mg $100 \mathrm{~g}^{-1}$ memberikan area terbesar pada suhu diatas $80{ }^{\circ} \mathrm{C}$, semakin tinggi faktor suhu blansir dan semakin rendah waktu yang digunakan maka nilai vitamin $\mathrm{C}$ yang dimiliki semakin besar, hal tersebut menunjukkan pengaruh dari interaksi faktor yang diberikan terhadap vitamin C. Perubahan nilai vitamin C yang terjadi pada setiap perlakuan blansir ditunjukkan pada surface plot. Gambar 7 membentuk saddle point dengan fungsi $\mathrm{Y}=12,144$ $+1,834 \mathrm{x}_{1}+0,117 \mathrm{x}_{2}+1,441 \mathrm{x}_{1}^{2}-1,052 \mathrm{x}_{2}^{2}-1,540 \mathrm{x}_{1} \mathrm{x}_{2}$

Area berwarna merah-oranye menggambarkan kadar vitamin $\mathrm{C}$ yang lebih tinggi dibandingkan warna redup lainnya. Vitamin $\mathrm{C}$ mudah larut dalam air dan mudah rusak akibat pemanasan. Vitamin $\mathrm{C}$ cukup stabil dalam kaedaan kering dan dalam larutan asam, namun tidak stabil dalam

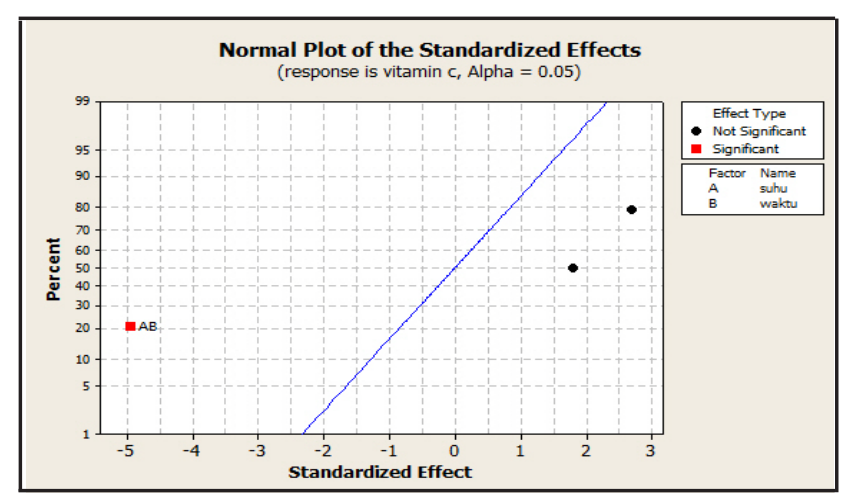

Gambar 4. Normal plot vitamin C cabai kering

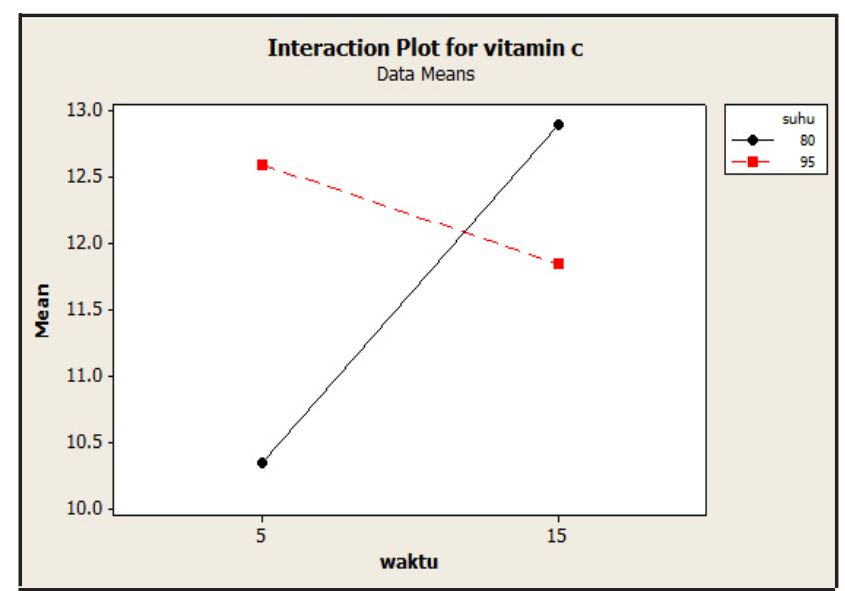

Gambar 5. Interaksi plot suhu dan waktu blansir terhadap vitamin C 
larutan alkali. Faktor yang menyebabkan kerusakan vitamin $\mathrm{C}$ adalah lama penyimpanan, perendaman dalam air, pemanasan dalam waktu lama, dan pemanasan dalam alat yang terbuat dari besi atau tembaga.

Burdurlu et al., (2006) mengatakan bahwa asam askorbat menurun dengan meningkatnya pemanasan. Sekitar setengah dari kandungan vitamin $\mathrm{C}$ akan rusak akibat pemanasan. Jumlah kandungan vitamin $\mathrm{C}$ yang hilang tergantung dari cara pemanasan yang dilakukan. Sumber vitamin C terdapat di dalam makanan terutama buahbuahan segar seperti jeruk, tomat, cabai, nanas, stroberi, dan sebagainya. Kadar vitamin $\mathrm{C}$ pada sayuran segar lebih rendah. Konsentrasi vitamin $\mathrm{C}$ yang paling tinggi pada buah-buahan segar terdapat pada kulitnya, sedangkan pada daging buah dan biji memiliki konsentrasi vitamin $\mathrm{C}$ yang rendah.

\section{Warna Cabai Merah Keriting}

Pemberian blansir bertujuan untuk mempertahankan warna untuk menghentikan reaksi browning pada saat cabai dikeringkan. Blansir juga biasa banyak digunakan untuk beberapa sayuran dan bahan pangan agar nilai kenampakan bahan pangan tersebut tinggi bila diukur secara objektif. Cabai merah keriting diukur menggunakan alat pengukur warna digital, yaitu menggunakan colour reader CR-10 dengan keluaran hasil berupa nilai L.a.b. Tingkat kecerahan digambarkan dengan huruf L, nilai a menunjukkan parameter campuran merah-hijau, nilai a positif penggambaran untuk warna lebih merah sedangkan a negatif untuk warna lebih hijau. Nilai b sebagai penggambaran parameter campuran kuning-biru, nilai b positif untuk warna lebih kuning dan nilai b negatif untuk warna lebih biru. Gambar 8 menunjukkan normal plot faktor untuk warna cabai kering.

Berdasarkan Gambar 9, diketahui bahwa faktor waktu (X2) yang berpengaruh signifikan terhadap warna chroma cabai kering. Parameter warna yang diambil untuk warna cabai yaitu nilai C (chroma), gabungan antara akar jumlah kuadrat nilai a dan b. Chroma merupakan ukuran yang paling penting untuk mengetahui tingkat warna buah buahan dan sayuran termasuk olahan tomat (Sanguansri et al., 1993). Nilai chroma dapat dihitung dengan rumus $\mathrm{C}=\left(\mathrm{a}^{2}+\mathrm{b}^{2}\right)^{0.5}$. Pengaruh suhu terhadap nilai warna terdapat pada Gambar 9, bahwa suhu 80 dan $95^{\circ} \mathrm{C}$ memiliki kenaikan kurva yang searah, walaupun nilai kenaikan berbeda. Interaksi tersebut menggambarkan bahwa suhu dan waktu blansir yang tinggi (95 ${ }^{\circ} \mathrm{C}$ dan 15 menit) yang digunakan, maka nilai warna yang dihasilkan semakin besar pula. Gambar 6 menunjukan main effect antara suhu dan waktu terhadap warna cabai kering. Berdasarkan Gambar 10, dapat terlihat jelas bahwa faktor suhu terhadap warna cabai kering tidak memberikan pengaruh nyata, sedangkan faktor waktu menggambarkan

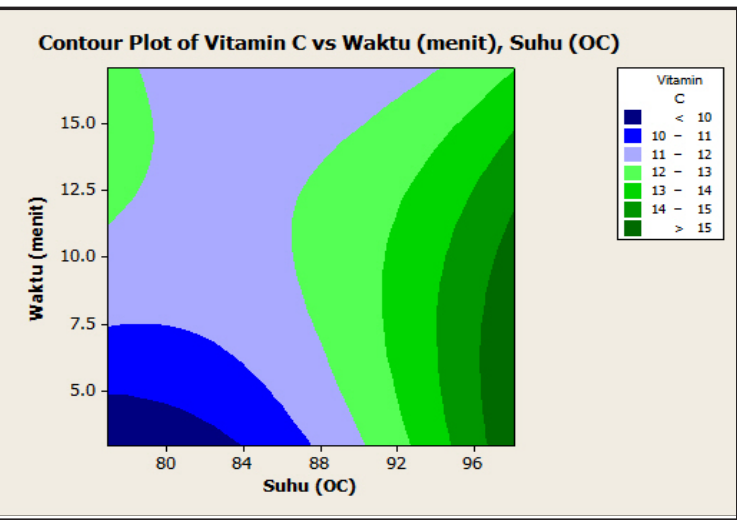

Gambar 6. Contour plot vitamin C cabai kering

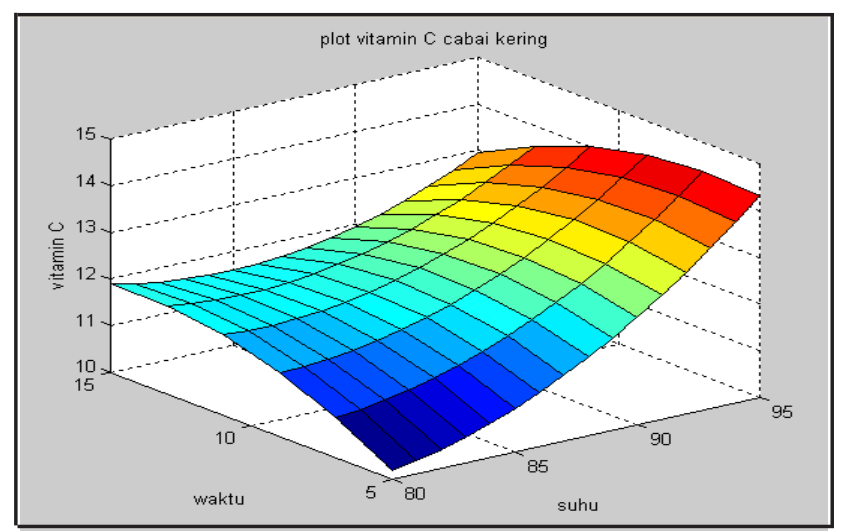

Gambar 7. Surface plot vitamin C cabai kering

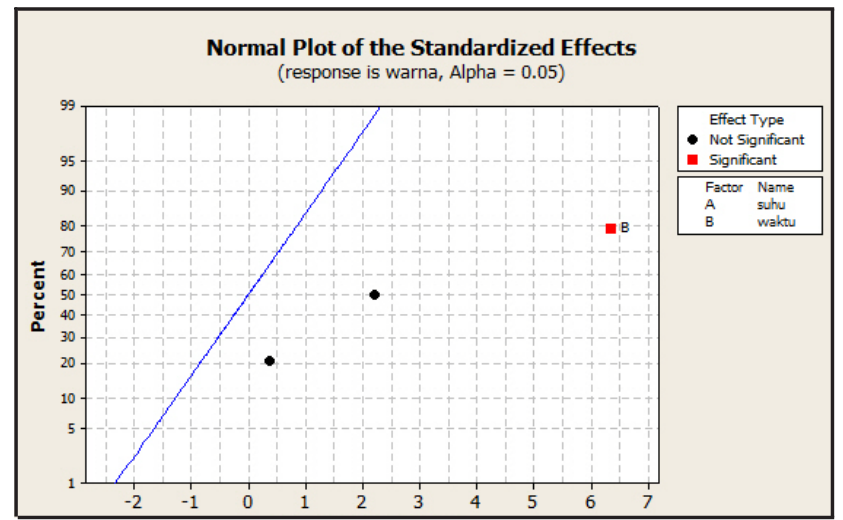

Gambar 8. Normal plot warna cabai kering

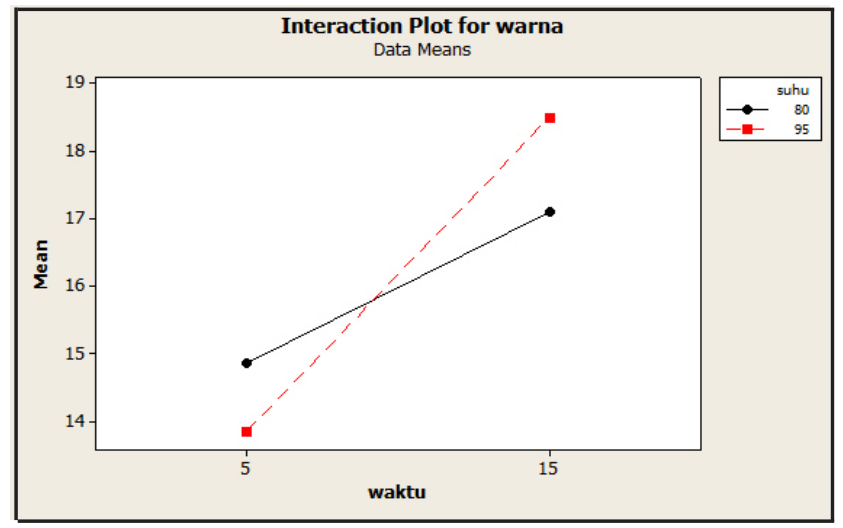

Gambar 9. Interaksi plot suhu dan waktu blansir terhadap warna 
kurva dengan perubahan ekstrim, jika waktu maksimum yang digunakan (15 menit), maka semakin besar nilai warna yang dihasilkan. Blansir dapat mencerahkan bahan pangan, hal ini terjadi karena penghilangan udara dan debu pada permukaan yang menyebabkan perubahan panjang gelombang cahaya yang dipantulkan (Fellows, 1990), semakin lama waktu yang diberikan pada saat blansir maka nilai chroma yang dihasilkan meningkat.

Gambar 11 menggambarkan contour plot cabai kering terhadap warna. Warna yang dihasilkan pada cabai merah keriting kering membentuk wilayah maksimum lokal dengan fungsi $Y=17.276-0.945 x_{1}+1.787 x_{2}-1.638 x_{1}^{2}-2.619 x_{2}^{2}$ $+0.934 \mathrm{x}_{1} \mathrm{x}_{2}$ seperti terlihat pada Gambar 12. Karotenoid merupakan kelompok pigmen yang berwarna kuning, oranye, merah oranye, serta larut dalam minyak (lipida). Karotenoid terdapat dalam buah papaya, kulit pisang, tomat, cabai merah, mangga wortel, ubi jalar, dan pada beberapa bunga yang berwarna kuning dan merah.

Karotenoid sangat sensitif terhadap panas, sehingga mudah sekali mengalami kerusakan akibat pemanasan. Kecerahan pada bahan pangan disebabkan karena pigmen yang terdapat pada kulit bahan pangan tersebut. Menurut Dutta et al., (2005), penurunan kandungan karotenoid tergantung dari suhu dan lama pengolahan, pemotongan atau penghancuran bahan. Hal yang dapat dilakukan dalam mengurangi kemungkinan kerusakan kandungan karotenoid adalah dengan mengurangi suhu dan lama pengolahan, serta mengurangi jeda waktu antara mengupas, memotong, dan menghancurkan bahan. Pengolahan dengan menggunakan suhu tinggi dalam waktu yang singkat merupakan alternatif yang baik dalam mengurangi penurunan kandungan karotenoid. Adapun plot variasi warna cabai dapat dilihat pada Gambar 12. Rendemen merupakan salah satu parameter respon terhadap faktor suhu (X1) dan waktu (X2) yang dianalisis meskipun tidak diamati, karena rendemen menjadi salah satu pertimbangan untuk diambilnya keputusan nilai optimal. Hasil analisis terhadap rendemen menunjukkan bahwa faktor suhu dan waktu blansir tidak berpengaruh nyata terhadap rendemen. Gambar 13 dan 14 merupakan normal plot suhu dan waktu terhadap rendemen.

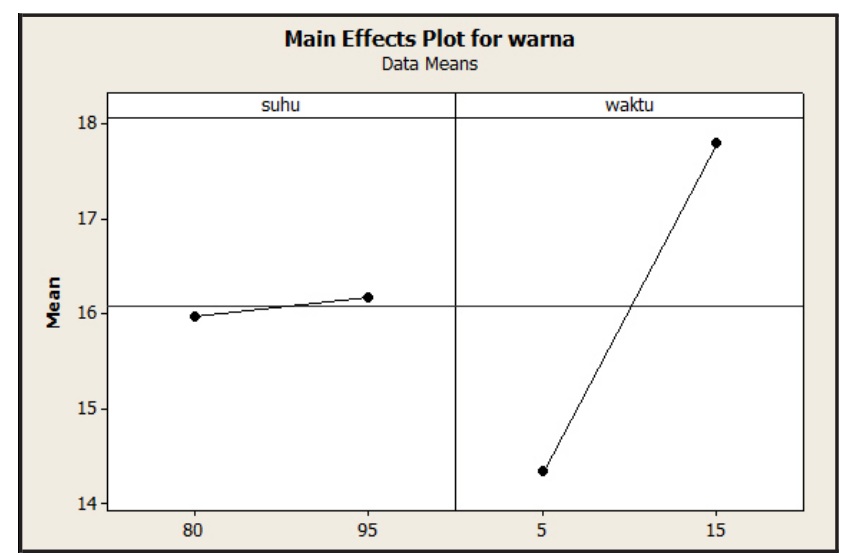

Gambar 10. Main effects warna cabai kering

\section{Optimasi Proses Blansir}

Model Responses Surface Metodhology (RSM) yang digunakan pada penelitian ini berfungsi untuk menemukan model optimasi dengan mendapatkan kondisi optimum dari faktor suhu dan lama blansir untuk mendapatkan respon terbaik.

\section{Vitamin C}

Vitamin C merupakan salah satu jenis vitamin yang mudah rusak dan larut dalam air. Blansir yang dilakukan dengan menggunakan steam atau kukus diharapkan mengurangi kerusakan kadar vitamin $\mathrm{C}$ yang terkandung pada bahan. Nilai Vitamin $\mathrm{C}$ cabai merah keriting yang dikeringkan dengan mesin pengering (tunnel dehydrator) mengalami kenaikan dari cabai sebelum dikeringkan. Waktu yang semakin lama pada suhu $95{ }^{\circ} \mathrm{C}$ dapat mengurangi nilai vitamin $\mathrm{C}$. Titik optimal untuk nilai vitamin $\mathrm{C}$ cabai merah keriting yang dikeringkan adalah blansir dengan suhu $98{ }^{\circ} \mathrm{C}$ selama 5 menit yaitu sebesar $15.9 \mathrm{mg} / 100$ gr. Nilai tersebut diperoleh dari model optimasi yang dihasilkan software minitab. Gambar 15 dan 16 merupakan gambar optimasi plot vitamin $\mathrm{C}$ cabai merah keriting kering.

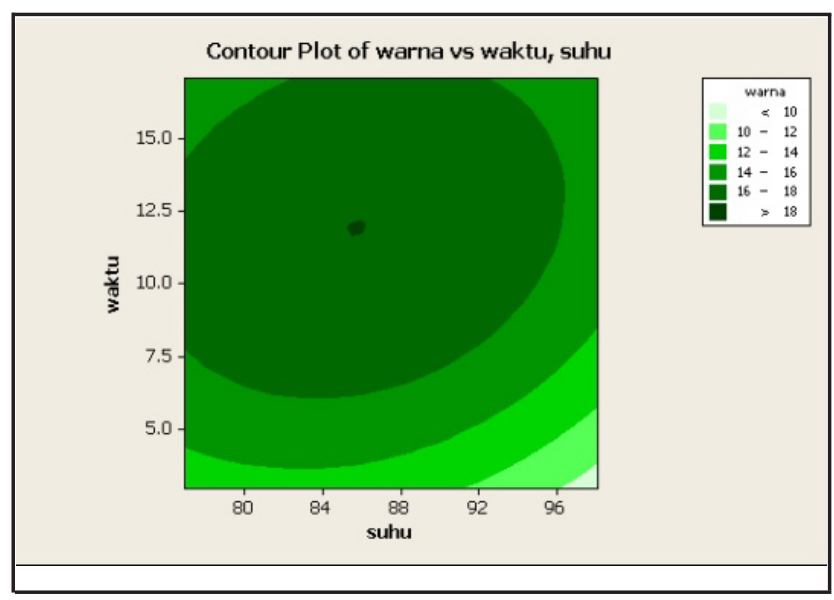

Gambar 11. Contour plot warna cabai kering

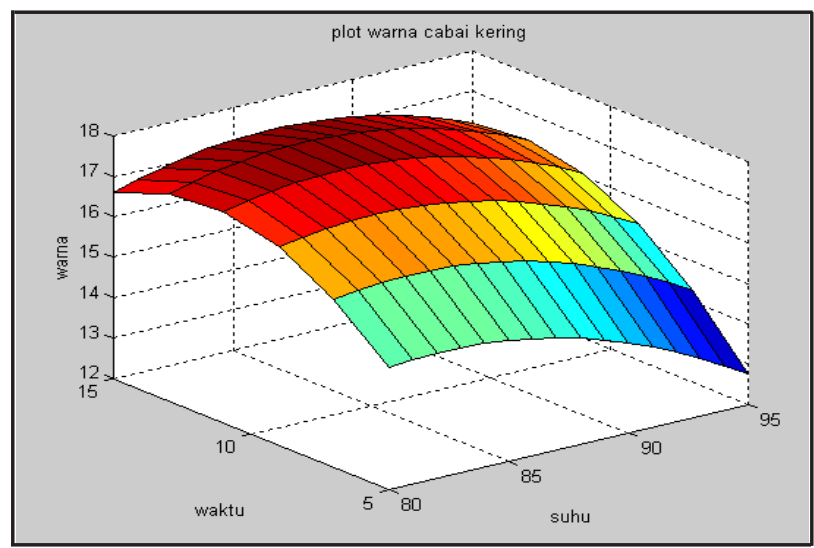

Gambar 12. Surface plot warna cabai kering 


\section{Warna}

Metode yang digunakan untuk mengukur warna yaitu menggunakan metode hunter scale. Nilai optimal untuk mendapatkan warna cabai merah kering tertinggi akan dicapai pada suhu sebesar $85{ }^{\circ} \mathrm{C}$ selama 12 menit dengan tingkat warna chroma yang akan dicapai sebesar 17.64. Hal ini dikarenakan derajat panas lebih tinggi daripada blansir dengan suhu $70{ }^{\circ} \mathrm{C}$ dengan pengukusan, sehingga menyebabkan semakin banyak enzim yang rusak. Oleh karena itu, kemungkinan terjadinya reaksi pencoklatan enzimatis lebih sedikit sehingga intensitas warna coklat semakin menurun.

Cabai merah keriting yang dikeringkan memiliki warna (chroma) yang relatif lebih kecil dibandingkan dengan warna cabai merah keriting segar. Penampakan yang dipantulkan oleh cabai kering lebih mendekati merah gelap. Reaksi pencoklatan enzimatis ataupun nonenzimatis merupakan satu-satunya penyebab terbentuknya warna coklat pada produk, hasil pengeringan cabai tidak menunjukan adanya reaksi pencoklatan, hal ini menggambarkan bahwa proses blansir dapat menghentikan aktifitas enzim sebelumnya.

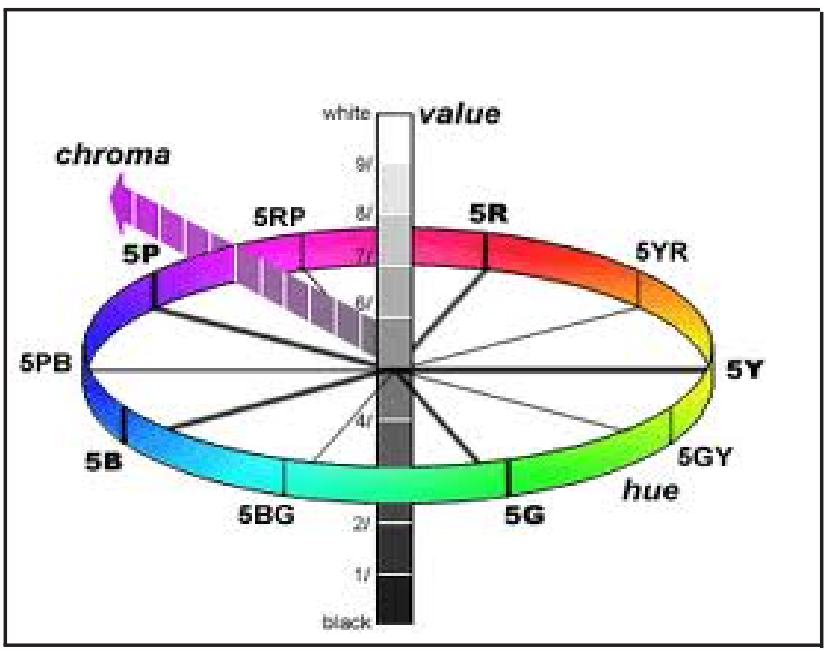

Gambar 13. Plot warna rendemen

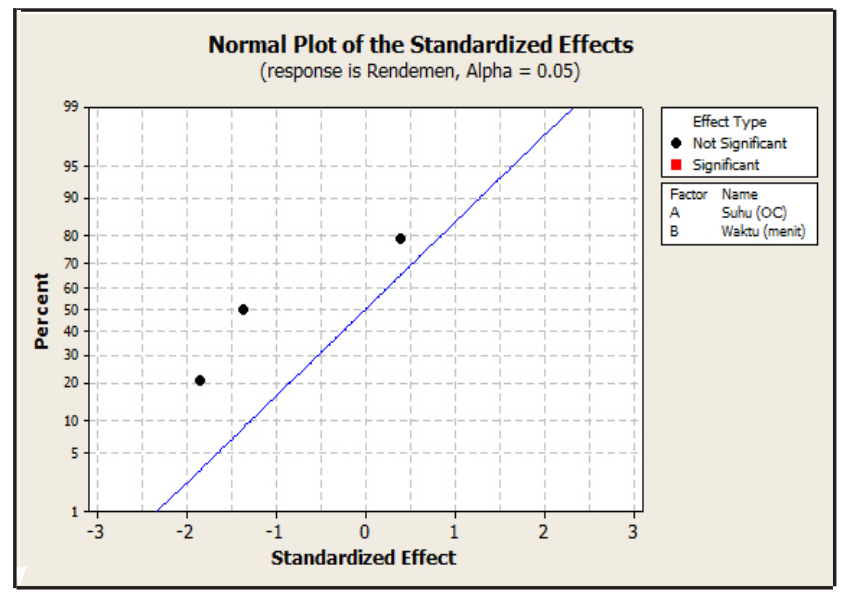

Gambar 14. Normal plot rendemen cabai
Kadar Air

Blansir menyebabkan penurunan kadar air dari cabai merah keriting. Hal ini terjadi karena proses blansir menyebabkan air yang terdapat dalam bahan pangan lebih mudah dikeluarkan sewaktu pengeringan. Blansir dimaksudkan untuk membuat sel-sel membran menjadi lebih permeablesehingga pergerakan air tidak terhambat (Gover, 1951). Kadar air yang diambil sebagai kadar terbaik berkisar antara 2-8\% sebagai hasil akhir pengeringan, kiarena aman dari resiko adanya pertumbuhan organisme kontaminan. Nilai optimal suhu dan waktu blansir pada cabai merah keriting segar kering terdapat pada suhu $77^{\circ} \mathrm{C}$ selama 15 menit agar menghasilkan kadar air optimal sebesar $10.0 \%$ (db). Terdapat dua macam jenis air pada bahan, yaitu air terikat dan air tidak terikat. Pengeringan merupakan salah satu cara yang dilakukan untuk dapat mengurangi air yang terkandung pada bahan. Pengeringan merupakan proses penurunan kadar air sampai batas tertentu dimana dapat mengurangi kerusakan bahan akibat aktifitas biologis dan kimia (Brooker et al., 1974).

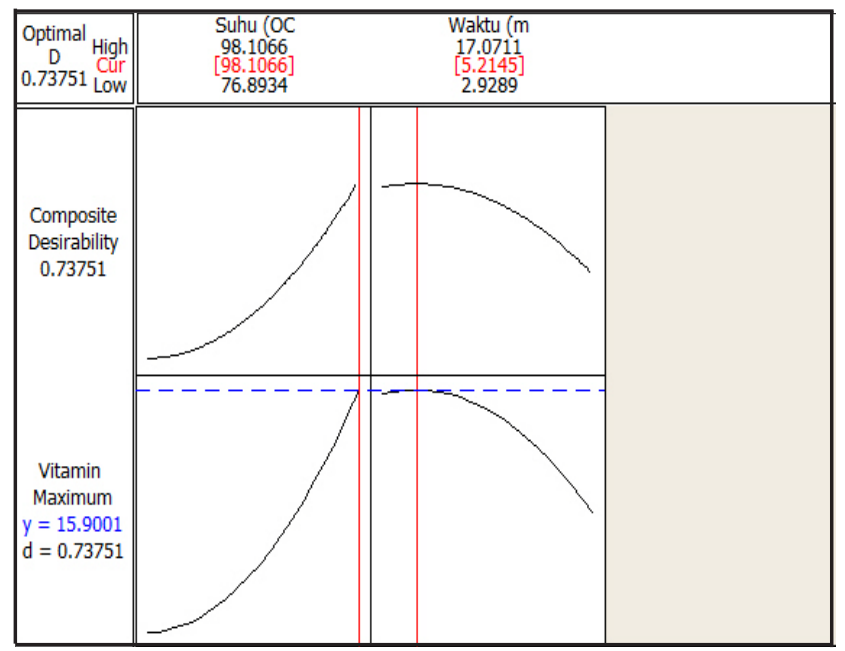

Gambar 15. Optimasi plot vitamin C cabai kering

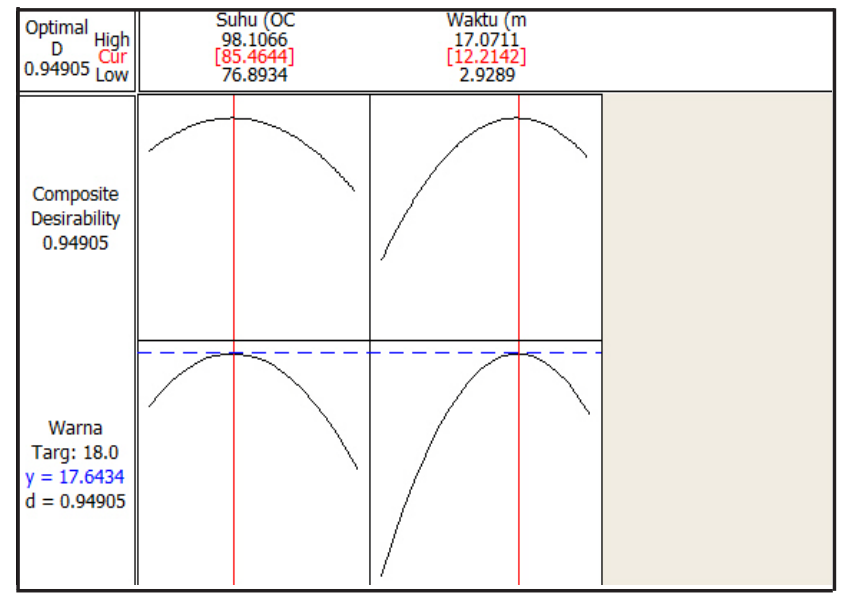

Gambar 16. Optimasi plot warna cabai kering 


\section{Optimasi Global}

Parameter cabai merah keriting yang dikeringkan dengan sebelumnya mendapat perlakuan blansir yaitu besarnya nilai vitamin $\mathrm{C}$ dan penampakan warna chroma yang tinggi serta dengan nilai kadar air yang paling rendah, rendemen yang dihasilkan untuk mendapatkan pengeringan cabai merah yang paling baik juga menjadi salah satu pertimbangan diambilnya titik optimal suhu dan waktu blansir. Hasil optimal ketiga parameter respon tersebut akan didapatkan pada suhu $98{ }^{\circ} \mathrm{C}$ selama 11 menit. Warna yang akan dihasilkan sebesar 15.06, vitamin C $15.16 \mathrm{mg} / 100 \mathrm{gr}$ dengan kadar air 7.7\% (db) dan rendemen 18.7\% (Gambar 17 dan 18).

\section{Validasi Kondisi Optimum}

Validasi dilakukan untuk menguji kebenaran dari

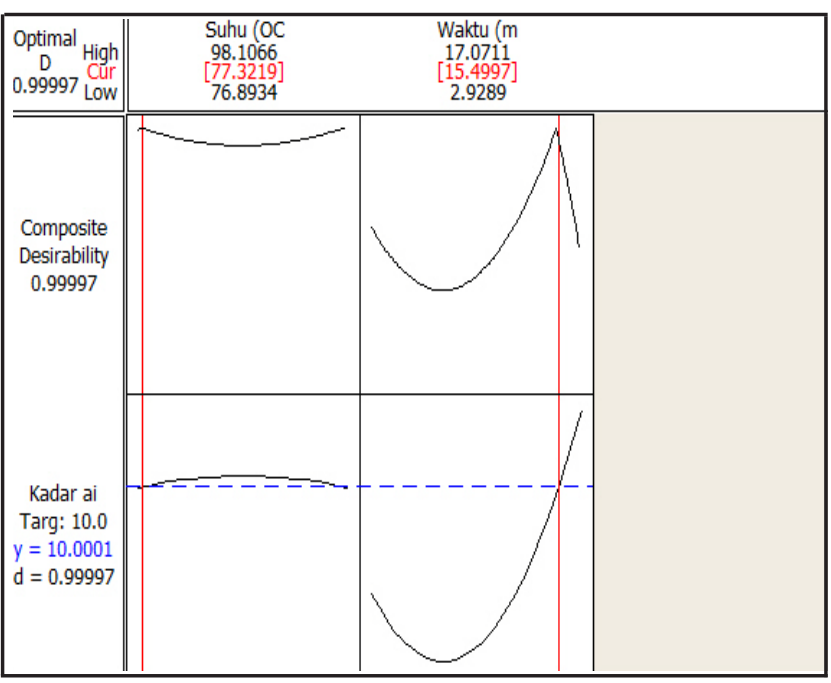

Gambar 17. Optimasi plot warna cabai kering

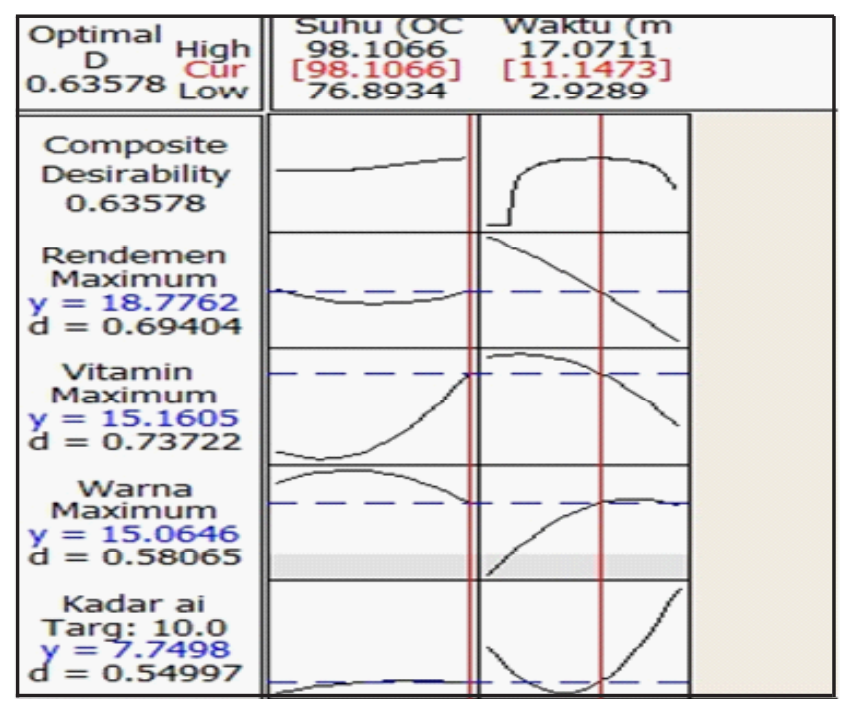

Gambar 18. Optimasi plot warna cabai kering kondisi optimum yang dihasilkan pada model statistika yang digunakan. Nilai toleransi yang diberikan sebesar $10 \%$ dari nilai prediksi. Nilai respon yang dihasilkan dari hasil validasi kondisi optimum menggunakan cabai merah keriting varietas TM 999. Nilai yang dihasilkan mendekati nilai prediksi dari model optimal. Hasil validasi tersebut disajikan pada Tabel 1 .

Gambar 1. Hasil validasi

\begin{tabular}{cccccc}
\hline & \multirow{5}{*}{ Nilai validasi } \\
\cline { 3 - 6 } Suhu $\left({ }^{\circ} \mathrm{C}\right)$ & $\begin{array}{c}\text { Waktu } \\
\text { (menit) }\end{array}$ & $\begin{array}{c}\text { Warna } \\
\text { (Chroma) }\end{array}$ & $\begin{array}{c}\text { Vit. C } \\
(\mathrm{mg} / 100 \text { gr })\end{array}$ & Ka (db) Rendemen \\
\hline 85 & 12 & 17.4 & & & \\
98 & 5 & & 15.2 & & 18.9 \\
98 & 11 & 15.1 & 16.7 & 5.3 & \\
98 & 3 & 16.7 & 13.2 & & \\
\hline
\end{tabular}

\section{KESIMPULAN}

Blansir merupakan proses pra pengeringan yang diberikan pada cabai merah keriting. Faktor reaksi yang diberikan pada penelitian ini adalah suhu blansir (X1) dan waktu blansir (X2), sedangkan respon yang diinginkan adalah kadar air, vitamin $\mathrm{C}$ dan warna. Faktor reaksi yang diberikan terbukti mempengaruhi respon variabel. Kondisi optimum yang dihasilkan berdasarkan pada keinginan nilai gizi yang ingin dicapai, yaitu pertimbangan kadar air minimum, rendemen yang tinggi serta warna dan nilai vitamin $\mathrm{C}$ yang terbaik.

Penelitian cabai merah keriting kering mendapatkan kondisi optimum pada suhu dan lama blansir sebesar 98 ${ }^{\circ} \mathrm{C}$ selama 11 menit. Kadar vitamin $\mathrm{C}$ yang akan dihasilkan pada cabai kering sebesar 15 mg/100 gr, rendemen yang dihasilkan sebesar $18 \%$, Kadar air minimum $7 \%(\mathrm{db})$ dan warna chroma 17 . Kadar air pada pengeringan cabai tidak dijadikan reaksi terhadap faktor yang diteliti, namun tetap diuji sebagai batasan standar mutu menurut SNI.

\section{DAFTAR PUSTAKA}

[AOAC] Association of Official Agricultural Chemist. 1984. Official Nethods of Analysis. Washington DC, USA.

Barus, M.V. 2009. Studi tentang pengetahuan dan tata cara engelolaan petani cabai di Desa Batu Karang, Kecamatan Payung, Kabupaten Karo [skripsi]. Medan : Program Sarjana, Universitas Sumatera Utara.

Brooker, D.B. 1974. Drying Cereal Grains. The AVI Publishing Company, Inc. Westport. Connecticut.

Burdurlu, H.S., N. Koca, F. Karadeniz. 2006. Degradation of vitamin $\mathrm{C}$ in citrus juice concentrates during storage. J Food Eng 74 (2) : 211-216. 
Dutta, D., U.R. Chaudhuri, R. Chakraborty R. 2005. Structure, health benefits, antioxidant property and processing and storage of carotenoids. African J Biotech 4 (13):1.510-1.520.

Fellows P. 1990. Food Processing Technology Principles and Practice. Ellis Horwood Ltd. England.

Jacobs, MB. 1958. The chemical Analysis of Food and Food Products, $2^{\text {nd }}$ Ed. New York : D. Van Nostrand Co., Inc.
Sanguansri, L., I. Gould, P. Drew. 1995. Improved Quality for Dryed Tomatoes. Final Report No. TM-304, Australian Food Industri Science Centre, Werribee, Victoria.

Winarno, F.G. 1980. Kimia Pangan dan Gizi. Jakarta: Gramedia. 